\title{
Effect of aromatase inhibitor on oestrogen production in rabbit blastocysts
}

\author{
J. T. Wu and Guey-Meei Lin
}

Worcester Foundation for Experimental Biology, Shrewsbury, Massachusetts 01545, U.S.A.

\begin{abstract}
Summary. Oestradiol-17 $\beta$ was produced by cultures of 5- and 6-day rabbit blastocysts containing $0.5-1 \mu \mathrm{M}-\left[{ }^{3} \mathrm{H}\right]$ testosterone. Addition of the aromatase inhibitor 4-hydroxy-4-androstene-3,17-dione at 3.5-7 $\mu \mathrm{M}$ reduced oestradiol production by $66-73 \%$ but had no effect on the size of blastocyst. Injection of $6 \mathrm{mg}$ 4-OH-androstenedione or 5-10 mg 4-acetoxy-4-androstene-3,17-dione, into the uterine lumen on Day 5 did not interfere with implantation. The functional significance of blastocyst oestrogen in rabbit remains obscure.
\end{abstract}

\section{Introduction}

It has been postulated that mammalian embryos produce oestrogen required for their own development and implantation (Dickmann, Dey \& Sen Gupta, 1976). Chemical evidence for steroidal production and metabolism has not been available for mouse embryos (Chew \& Sherman, 1975; Sherman \& Atienza, 1977; Antila, Koskinen, Niemelä \& Saure, 1977; Grube, Gwazdauskas, Lineweaver \& Vinson, 1978) although testosterone is converted to oestradiol-17 $\beta$ before and during the time of implantation of rabbit blastocysts (George \& Wilson, 1978).

The present study was designed to determine whether: (1) 4-hydroxy-4-androstene-3,17dione, an aromatase inhibitor (Brodie, Schwarzel, Shaikh \& Brodie, 1977; Brodie, Marsh, Wu \& Brodie, 1979), could alter oestradiol production in rabbit blastocysts in culture; (2) a reduced oestradiol production in rabbit blastocysts affects development in vitro; and (3) intrauterine injection of aromatase inhibitors interferes with implantation.

\section{Materials and Methods}

\section{In-vitro culture of blastocysts}

Mature mixed-breed rabbits were killed at various times on Days 5, 6 or 7 of pregnancy (Day 0 =mating). The uteri were trimmed and flushed with Eagle's minimum essential medium supplemented with bovine serum albumin $(10 \mathrm{mg} / \mathrm{ml})$ and gentamycin $(60 \mu \mathrm{g} / \mathrm{ml})$. The blastocysts were picked up from the uterine washings and rinsed in 2 changes of the medium. Blastocysts in groups of 10-20 were transferred into a glass scintillation vial containing 4-5 ml of the above medium and $0.5-1.0 \mu \mathrm{M}\left[1 \alpha, 2 \alpha_{-}{ }^{3} \mathrm{H}\right]$ testosterone (sp. act. $50 \mathrm{Ci} / \mathrm{mmol}$ ) or $\left[1,2,6,7-{ }^{3} \mathrm{H}\right]-$ testosterone (sp. act. $100 \mathrm{Ci} / \mathrm{mmol}$ ) (New England Nuclear, Boston), with or without 3.5$7.0 \mu \mathrm{M}$-androstenedione. A vial containing the medium and tritiated testosterone together with the second blastocyst washings but without embryos served as the control. In each pair of cultures (i.e. with or without androstenedione) the conditions such as the number and the size of blastocysts, and the amount of medium, were kept as similar and as constant as possible. The cultures were maintained at $37^{\circ} \mathrm{C}$ in an atmosphere of $5 \% \mathrm{CO}_{2}$ in air for various periods of time. The amount of testosterone present at the end of culture was still $75-88 \%$ of the total radioactivity, indicating that it was not depleted. 
The effects of androstenedione in culture were evaluated in terms of blastocyst size (diameter) and oestrogen synthesis. The diameters of blastocysts were measured under a dissecting microscope $(\times 4-16)$; blastocysts that collapsed in culture and during handling $(<5 \%)$ were excluded. After measurement, the culture media (together with the blastocysts) were frozen at $-20^{\circ} \mathrm{C}$ until extracted for steroids.

\section{Extraction and chromatography of steroids}

The culture media were thawed at room temperature, and vortexed to rupture the blastocysts. An aliquot of $0 \cdot 2-1 \mathrm{ml}$ was then taken from each culture vial. After the addition of $20000-200000$ d.p.m. $\left[{ }^{14} \mathrm{C}\right]$ oestradiol, the medium was extracted 4 times, each with 10 volumes of ether ( $85-90 \%$ of the radioactivity was extracted by this procedure). The extracts were dried under nitrogen and reconstituted in 100 or $200 \mu \mathrm{l}$ alcohol. Duplicate 1-10 $\mu \mathrm{l}$ aliquots were counted for ${ }^{3} \mathrm{H}$ and ${ }^{14} \mathrm{C}$ radioactivities for estimation of total recovery. Aliquots of extracts were applied onto Silica Gel 60 F-254 plates (EM Labs) and developed in one of the following solvent systems: dichloromethane:ether $(8: 2 \mathrm{v} / \mathrm{v})$; dichloromethane:ethylacetate:methanol ( $85: 15: 1$ by vol.); $3 \%$ methanol in chloroform; ethyl acetate:benzene $(3: 7 \mathrm{v} / \mathrm{v})$; and ether alone. The areas corresponding to authentic oestradiol were scraped and eluted with ether; ${ }^{3} \mathrm{H}$ and ${ }^{14} \mathrm{C}$ radioactivities in the eluate after drying were counted for estimation of total radioactivity. The fraction was then re-chromatographed once or twice in one of the other solvent systems and assayed for oestradiol by recrystallization to constant specific activity. Usually the amount of oestradiol in the control vials was not detectable; however, if present, it was always subtracted from the value for the experimental vials.

\section{Oestradiol determination by recrystallization to constant specific activity}

Duplicate aliquots of an oestradiol sample, about 30-60000 c.p.m. each, were placed in 5 -ml vials. To each was added $120 \mathrm{mg}$ unlabelled oestradiol and $3000-6000$ c.p.m. $\mid{ }^{14} \mathrm{Cl}-$ oestradiol. The mixture was dissolved in $3 \mathrm{ml}$ alcohol at $70^{\circ} \mathrm{C}$ and $50 \mu \mathrm{l}$ of the solution were removed for counting the total radioactivity $\left({ }^{3} \mathrm{H}\right.$ and ${ }^{14} \mathrm{C}$ counts). The remaining solution was cooled slowly until crystals appeared. The volume of alcohol was reduced slowly to $1 \mathrm{ml}$ under a gentle nitrogen stream, and the vial was chilled in the ice bath for $10 \mathrm{~min}$. The mother liquor was placed in a vial and a small amount $(\sim 5 \mathrm{mg})$ of the crystal was placed in another vial. The remaining crystals were re-dissolved in the alcohol with the aid of heating. The recrystallization procedures were repeated as many times as the sample allowed. The mother liquor and crystal samples were dried, dissolved in the scintillant ACS (Amersham) and counted for 10-20 min in a Beckman liquid scintillation counter (LS 8000) at $40-50 \%$ efficiency. The ${ }^{3} \mathrm{H} /{ }^{14} \mathrm{C}$ ratios or specific activities were considered constant if there was $<8 \%$ variation between sequential samples (George \& Wilson, 1978).

\section{Oestradiol determination by radioimmunoassay}

Because of the tedious and time-consuming nature of the recrystallization procedure, oestradiol content in the isolated fractions was also determined by radioimmunoassy. Oestradiol recovery rates were estimated indirectly by placing a known amount of $\left|{ }^{3} \mathrm{H}\right|$ oestradiol or $\left[{ }^{14} \mathrm{Cloestradiol}\right.$ in an equivalent volume of medium which was then extracted and chromatographed exactly the same as the experimental samples so that the assay would not be complicated by the presence of external $\left[{ }^{14} \mathrm{C}\right]$ oestradiol or $\left[{ }^{3} \mathrm{H} \mid\right.$ oestradiol.

The oestradiol in the samples was already labelled with ${ }^{3} \mathrm{H}$ and was quantitated by: (1) treatment with antiserum to oestradiol; (2) treatment with charcoal to absorb the free steroids; (3) measurement of radioactivity in the supernatant that contained the $\left|{ }^{3} \mathrm{H}\right|$ oestradiol-antibody 
complex; and (4) conversion of radioactivity into pg oestradiol, taking into consideration the antibody-binding efficiency at the corresponding oestradiol concentration and the specific activity of $\left[{ }^{3} \mathrm{H}\right.$ loestradiol derived from the $\left[{ }^{3} \mathrm{H} \mid\right.$ testosterone used. The latter was estimated from the positions of ${ }^{3} \mathrm{H}$ and their relative distribution in the $\left|{ }^{3} \mathrm{H}\right|$ testosterone. For example, oestradiol produced from $\left|1 \alpha, 2 \alpha-{ }^{3} \mathrm{H}\right|$ testosterone had the same specific activity as the substrate testosterone itself, while oestradiol produced from $\left[1,2,6,7-{ }^{3} \mathrm{H}\right]$ testosterone had a specific activity of $68 \%$ of the radioactivity of testosterone. In the latter, $40 \%$ of the ${ }^{3} \mathrm{H}$ is at the $\mathrm{C} 1$ and $\mathrm{C} 2$ positions and $60 \%$ at the $\mathrm{C} 6$ and $\mathrm{C} 7$ positions. At $\mathrm{C} 1$ and $\mathrm{C} 2,80 \%$ of the ${ }^{3} \mathrm{H}$ belongs to $\beta$ hydrogen which is preferentially removed during aromatization. The antibody binding efficiency was estimated from a standard curve constructed from $0 \cdot 15$ to $64 \mathrm{pg}\left[2,4,6,7-{ }^{3} \mathrm{H}\right]$ oestradiol (sp. act. $92 \mathrm{Ci} / \mathrm{mmol}$; New England Nuclear).

The assay procedures were as follows. The antiserum, batch $\mathrm{E}_{2} \mathrm{TG}-\mathrm{K}$ (Wright, Collins \& Preedy, 1978), was used at a concentration of $1: 30000$ in the assay buffer. For each oestradiol sample, two aliquots $(10000$ and 20000 d.p.m.) were placed in separate glass tubes $(12 \times$ $75 \mathrm{~mm}$ ), dried under nitrogen gas, dissolved in $0.5 \mathrm{ml}$ assay buffer at $40^{\circ} \mathrm{C}$, and dispensed as follows: (1) $0.1 \mathrm{ml}$ for counting of radioactivity; (2) $0.1 \mathrm{ml}$ sample plus $0.1 \mathrm{ml}$ buffer for the detection of nonspecific binding and (3) $0.1 \mathrm{ml}$ sample plus $0.1 \mathrm{ml}$ antiserum, in duplicate for the determination of specific binding. Both (2) and (3) were incubated at $50^{\circ} \mathrm{C}$ for $10 \mathrm{~min}$, followed by $30 \mathrm{~min}$ at $30^{\circ} \mathrm{C}$, and cooled in a $4^{\circ} \mathrm{C}$ ice bath for $5 \mathrm{~min}$. Then $0.7 \mathrm{ml}$ of a suspension of ice-cold $1 \%$ charcoal in the assay buffer was added to each tube. The tubes remained in the ice bath for an additional $10 \mathrm{~min}$, followed by centrifugation at $1000 \mathrm{~g}$ at $4^{\circ} \mathrm{C}$ for $5 \mathrm{~min}$. A $0.5 \mathrm{ml}$ aliquot of supernatant was removed from each tube and placed in a mini-vial. After addition of $5 \mathrm{ml}$ counting scintillant (ACS, Amersham) and thorough mixing, the vials were counted for 10 or $20 \mathrm{~min}$ in a liquid scintillation counter (Beckman LS 8000 ) at $33-37 \%$ efficiency. The nonspecific binding was generally $<1 \%$.

\section{Effect of intraluminal injection of aromatase inhibitors on implantation}

Female rabbits on Day 5 of pregnancy were anaesthetized with pentobarbitone sodium and a midline incision was made in the lower abdomen to expose the uterine horns. One horn was injected, from the oviducal end, with $6 \mathrm{mg} \mathrm{4-OH}$-androstenedione or 5-10 mg 4-acetoxyandrostenedione in $0.1 \mathrm{ml}$ suspension medium while the other horn was injected with $0.1 \mathrm{ml}$ suspension medium to serve as the control. The suspension medium consisted of 1 part Steroid Suspending Vehicle (National Cancer Institute: carboxymethylcellulose-7, $4 \mu \mathrm{l}$ polysorbate $80,9 \mu \mathrm{l}$ benzyl alcohol and water to make up $1 \mathrm{ml})$ and 1 part $0.9 \% \mathrm{NaCl}(\mathrm{v} / \mathrm{v})$. Treatment was alternated between the right and the left horn in succeeding animals. On Day 8 the rabbits were killed, the ovaries were examined for corpora lutea (CL), and the number and width (or the larger axis) of the implantation sites were recorded.

\section{Statistical analysis}

The data were analysed by the paired $t$ test.

\section{Results}

Determination of $\left[{ }^{3} \mathrm{H}\right.$ loestradiol content by co-crystallization with $\mid{ }^{14} \mathrm{C}$ loestradiol to constant specific activity

There has been some doubt about the accuracy of this method. To evaluate this problem, 3 trial samples were prepared by varying the proportions of $\left[{ }^{3} \mathrm{H}\right]$ oestradiol and $\left[{ }^{3} \mathrm{H} \mid\right.$ testosterone and their $\left[{ }^{3} \mathrm{H}\right]$ oestradiol contents were assayed by co-crystallization with $\left[{ }^{14} \mathrm{C}\right.$ loestradiol to con- 
stant specific activity. As shown in Table 1, the observed values were very close to the expected ones, indicating that the method is accurate and reliable. If the ${ }^{3} \mathrm{H} /{ }^{14} \mathrm{C}$ ratios of the samples were standardized and the crystal and mother liquor fractions during recrystallization were plotted (Text-fig. 1), more crystallizations were needed to reach a constant ${ }^{3} \mathrm{H} /{ }^{14} \mathrm{C}$ ratio as the oestradiol content became lower. The recrystallization results of 3 experiments dealing with Sample B containing $66 \cdot 1 \%$ oestradiol are shown in Text-fig. 2 ; the results were highly reproducible.

In comparison with the radioimmunoassay, recrystallization required much larger amounts of samples. It was, however, the method of choice when the oestradiol values determined by assay appeared unusually low and the samples were suspected of being contaminated with unlabelled oestradiol used as the standard in the tlc. Otherwise, in the regular samples, the values determined by the two methods did not vary by more than $10 \%$.

Table 1. Determination of $\left[{ }^{3} \mathrm{H} \mid\right.$ oestradiol by co-crystallization with $\left[{ }^{14} \mathrm{C}\right]$ oestradiol

\begin{tabular}{ccccccc}
\hline & \multicolumn{2}{c}{ Sample composition } & & & \\
Sample & $\begin{array}{c}{ }^{3} \mathrm{H} \mid \text { Oestradiol } \\
\left(\text { c.p.m. } \times 10^{-3}\right)\end{array}$ & $\begin{array}{l}{ }^{3} \mathrm{H} \mid \text { Testosterone } \\
\left.\text { (c.p.m. } \times 10^{-3}\right)\end{array}$ & & Starting & At constancy & $\begin{array}{c}\text { Oestradiol content (\%) } \\
\text { (mean } \pm \text { s.e.m.) }\end{array}$ \\
\hline A & $101(97 \cdot 1 \%)^{*}$ & 3 & $3.04 \pm 0.04$ & $2.86 \pm 0.05$ & $94.2 \pm 2.2(n=3)$ \\
B & $111(66.1 \%)$ & 57 & $3.57 \pm 0.04$ & $2.34 \pm 0.04$ & $65.5 \pm 0.8(n=3)$ \\
C & $87(28.1 \%)$ & 223 & $5.43 \pm 0.07$ & $1.59 \pm 0.08$ & $29.2 \pm 1.2(n=3)$ \\
\hline
\end{tabular}

* The value in parentheses denotes the percentage of oestradiol in the total tritium radioactivity.

$\dagger$ The ratio is calculated from the respective c.p.m.

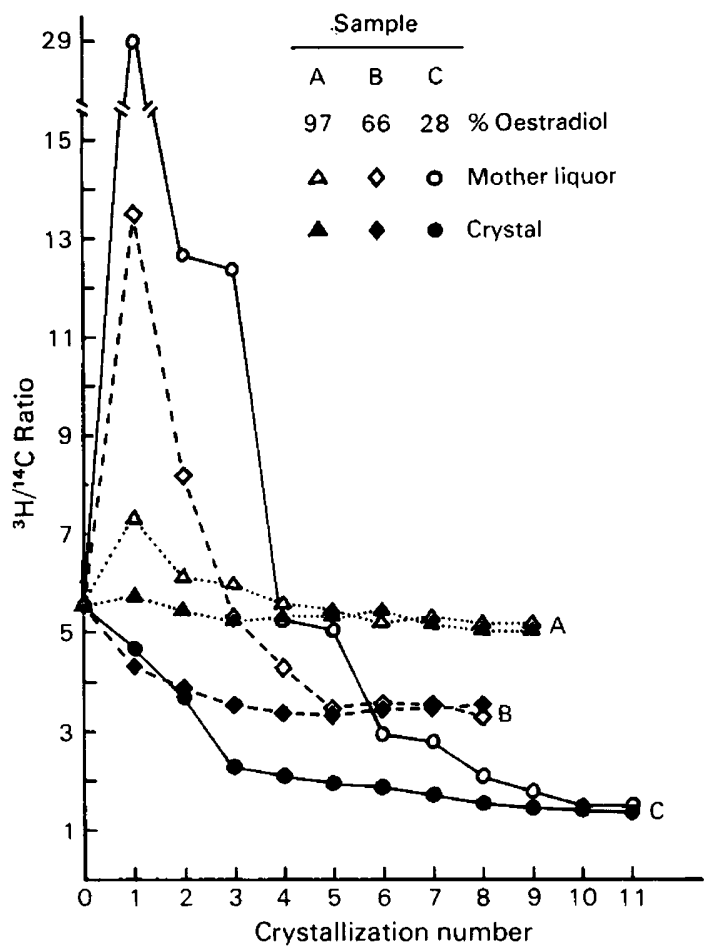

Text-fig. 1. Co-crystallization with $\mid{ }^{1+} \mathrm{C}$ loestradiol to constant specific activity of samples containing various proportions of $\mid{ }^{3} \mathrm{H}$ loestradiol. The ${ }^{3} \mathrm{H} /{ }^{1+} \mathrm{C}$ ratios for Samples A and B were multiplied by 1.87 and 1.30 respectively, to be comparable to the starting ratio $(5.50)$ for Sample C. The values were from individual experiments, not the means listed in Table 1 . 


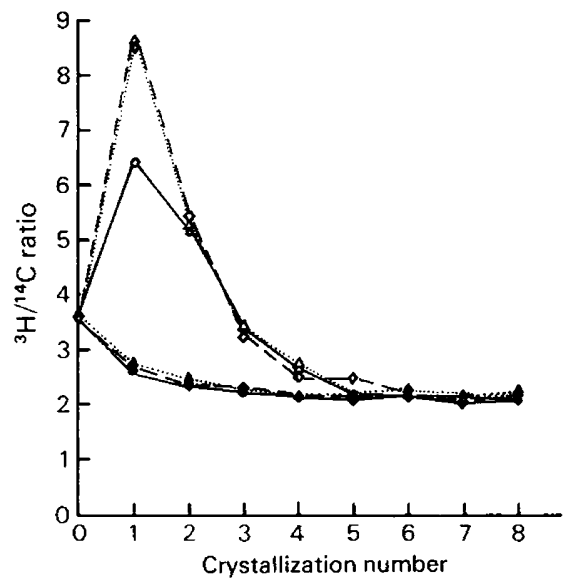

Text-fig. 2. Co-crystallization with $\left[{ }^{14} \mathrm{C} /\right.$ oestradiol to constant specific activity of 3 subsamples from Sample B shown in Text-fig. 1. Open symbols, mother liquor; closed symbols, crystals.

\section{Radioimmunoassay of oestradiol}

According to Wright et al. (1978), the antiserum $\mathrm{E}_{2} \mathrm{TG}-\mathrm{K}$ was highly specific and showed low cross-reactions to testosterone $(<0.1 \%)$, oestrone $(1.81 \%)$; oestriol $(0.77 \%)$, oestradiol- $17 \alpha$ $(0.73 \%)$, progesterone $(0.39 \%)$ and dehydroepiandrosterone $(<0.1 \%)$. Purification of the samples by thin-layer chromatography reduced further the likelihood of interference from the presence of cross-reacting compounds in the oestradiol samples. According to our experience (Text-fig. 3) the binding efficiency appeared more variable when the amounts of oestradiol were $\leqslant 0.15 \mathrm{pg}$, but it was quite consistent and remained at plateau value $(83-86 \%)$ when oestradiol fell within the range of 0.27 to $2.4 \mathrm{pg} /$ tube. The binding efficiency then declined sharply from 12 to $67 \mathrm{pg} /$ tube. In the repeating assays the amount of oestradiol in the sample tube was adjusted to the range where the binding efficiency was at or near the plateau. The assay was very specific as indicated by the fact that if the samples were mixed with unlabelled oestradiol (e.g. as carrier steroid during purification by chromatography) then the amount of $\left[{ }^{3} \mathrm{H}\right]$ oestradiol detected was reduced to nil. Using the method of Abraham, Swerdloff, Tulchinsky \& Odell (1971) the intra-assay coefficient of variation calculated from 9 duplicate determinations, ranging from 0.15 to $67 \mathrm{pg} /$ tube, was 6.6 and $7.8 \%$, respectively for 2 assays while the inter-assay coefficient of variation was $10.5 \%$. The direct assay as described here should have a higher precision than the regular radioimmunoassay as the latter has one more variable than the former, i.e. the addition of radioactive tracer steroid to the sample tube.

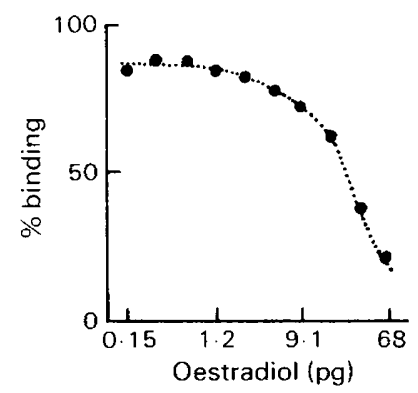

Text-fig. 3. Binding curve of the antiserum $E_{2} T G-K$ used in the radioimmunoassay for oestradiol-17 $\beta$. 


\section{Effect of aromatase inhibitor on the diameter and oestradiol production of cultured blastocysts}

As shown in Table 2, when blastocysts were recovered on Days 5 and 6 , and cultured in medium with or without $4-\mathrm{OH}$-androstenedione for up to $48 \mathrm{~h}$, there were no significant differences in blastocyst diameters.

The amount of oestradiol production appeared to increase with age and the size of blastocysts (Table 3): oestradiol production was decreased by 4-OH-androstenedione.

Table 2. Size of rabbit blastocysts after culture with 4-hydroxyandrostenedione (4-OH-A)

\begin{tabular}{|c|c|c|c|c|}
\hline \multirow[b]{2}{*}{ Group } & \multirow{2}{*}{$\begin{array}{l}\text { Time of } \\
\text { blastocyst } \\
\text { recovery }\end{array}$} & \multirow{2}{*}{$\begin{array}{l}\text { Hours in } \\
\text { culture }\end{array}$} & \multicolumn{2}{|c|}{ Blastocyst diam. (mm) } \\
\hline & & & Without 4-OH-A & With 4-OH-A \\
\hline \multirow[t]{2}{*}{1} & 5 days $18 \mathrm{~h}$ & 24 & $2.9 \pm 0.1(11)$ & $2 \cdot 8 \pm 0.1(10)$ \\
\hline & & 48 & $4 \cdot 1 \pm 0.4(11)$ & $3.6 \pm 0.3(10)$ \\
\hline 2 & 6 days $0 \mathrm{~h}$ & 14 & $3.6 \pm 0.2(18)$ & $3.8 \pm 0.2(17)$ \\
\hline 3 & 6 days $0 \mathrm{~h}$ & 48 & $4.7 \pm 0.2(33)$ & $4.8 \pm 0.2(34)$ \\
\hline 4 & 6 days $15 \mathrm{~h}$ & 32 & $4.4 \pm 0.3(10)$ & $4.5 \pm 0.3(12)$ \\
\hline
\end{tabular}

Values are mean \pm s.e.m. for the no. of blastocysts given in parentheses.

Table 3. Oestrogen synthesis by rabbit blastocysts

\begin{tabular}{|c|c|c|c|c|c|}
\hline \multirow[b]{2}{*}{ Group } & \multirow{2}{*}{$\begin{array}{l}\text { Time of } \\
\text { blastocyst } \\
\text { recovery }\end{array}$} & \multirow{2}{*}{$\begin{array}{l}\text { Hours } \\
\text { in } \\
\text { culture }\end{array}$} & \multicolumn{3}{|c|}{ Oestradiol production (pg/h/embryo) } \\
\hline & & & Without 4-OH-A & With 4-OH-A & $\%$ suppression \\
\hline 5 & 5 days $18 \mathrm{~h}$ & 24 & $0.94 \pm 0.21(3)$ & $0.25 \pm 0 \cdot 12^{*}(3)$ & 73 \\
\hline 6 & 6 days $0 \mathrm{~h}$ & $24-31$ & $5 \cdot 6 \pm 1 \cdot 3(3)$ & $1.9 \pm 0.6^{*}(3)$ & 66 \\
\hline 7 & 6 days $20 \mathrm{~h}$ & 96 & $10 \cdot 4(2)$ & & \\
\hline 8 & 7 days $0 \mathrm{~h}$ & 10 & $16 \cdot 7(1)$ & & \\
\hline
\end{tabular}

Values are mean \pm s.e.m. for the no. of determinations given.

${ }^{*} P<0.05$ compared with the value without $4-\mathrm{OH}-\mathrm{A}$.

\section{Effect of aromatase inhibitors on implantation}

As shown in Table 4, intrauterine injection of the 2 aromatase inhibitors did not affect the percentage of implantations or the size of implantation sites when compared to the control horn injected with vehicle alone. When the animals were killed on Day 8, the uterine horns still contained many of the whitish crystals of the inhibitors, indicating that sufficient amounts of the

Table 4. Implantation in rabbits treated with androstenedione aromatase inhibitors. 4-OH-A and 4-Ac-A

\begin{tabular}{|c|c|c|c|c|c|}
\hline \multirow[b]{3}{*}{ Group } & \multirow{2}{*}{\multicolumn{2}{|c|}{ Uterine horns }} & \multirow{3}{*}{$\begin{array}{c}\text { No. of } \\
\text { CL }\end{array}$} & \multicolumn{2}{|c|}{ Implantation sites } \\
\hline & & & & & Mean + s.e.m. \\
\hline & Treatment & No. & & No. $(\%$ of $C L)$ & size $(\mathrm{mm})$ \\
\hline \multirow[t]{2}{*}{9} & Vehicle & 6 & 28 & $23(82)$ & $10.9 \pm 0.4$ \\
\hline & $4-\mathrm{OH}-\mathrm{A}(6 \mathrm{mg})$ & 6 & 30 & $26(87)$ & $10 \cdot 2 \pm 0.3$ \\
\hline \multirow[t]{2}{*}{10} & Vehicle & 6 & 28 & $26(93)$ & $11 \cdot 8 \pm 0.3$ \\
\hline & 4-Ac-A (5-10 mg) & 6 & 31 & $31(100)$ & $12 \cdot 2 \pm 0.4$ \\
\hline
\end{tabular}


compounds had been administered. Similar crystals were not seen in the control horns, indicating that the crystals were not from components in the suspending vehicle. An additional 2 rabbits receiving a $20 \mathrm{mg}$ suspension of $4-\mathrm{OH}$-androstenedione in one horn also showed normal implantation on Day 8. The difference in the size of implantation sites between Groups 9 and 10 was probably due to the difference in the body size of the rabbits.

\section{Discussion}

Oestradiol detected in 5- and 6-day rabbit blastocysts was considered to be of embryonic (Dickmann et al., 1975) or maternal origin (Borland, Erickson \& Ducibella, 1977; Singh \& Booth, 1978). According to George \& Wilson (1978), rabbit blastocysts could convert testosterone into oestradiol at $0.2 \mathrm{pmol} / \mathrm{h} / \mathrm{embryo}$ on Day 7 , but not on Days 5 or 6 . Assuming that oestradiol was not further metabolized by the blastocyst, the oestradiol production in the 6 blastocysts recovered on Day 7 (Group 8) in the present study was $16.7 \mathrm{pg} / \mathrm{h} / \mathrm{embryo}$, only one-third the value reported by George \& Wilson (1978). When blastocysts of Groups 5 and 6 (Table 2) were cultured for $24 \mathrm{~h}$ or more, oestradiol was produced in low amounts in the culture medium. The blastocysts must therefore have developed the ability to synthesize oestradiol during the culture period or were already capable of synthesizing very small amounts of oestradiol which would have been difficult to detect in the 1-h culture period used by George \& Wilson (1978). The study of Gadsby, Heap \& Burton (1980) also suggested some aromatase activity in the 6-day blastocyst, but the amount of oestradiol obtained was not sufficient for positive identification and quantitation. On the other hand, Singh \& Booth (1978) did not find oestradiol synthesis in 6-day blastocysts cultured for $24 \mathrm{~h}$ with progesterone, dehydroepiandrosterone, androstenedione and testosterone. The reason for the discrepancies is not clear. However, Hoversland, Dey \& Johnson (1982) have shown that homogenates of Day 5 and 6 rabbit blastocysts had aromatase activities of 0.35 and $5.9 \mathrm{pg} / \mathrm{embryo} / \mathrm{h}$, respectively. These values are quite comparable to ours.

Oestradiol is taken up by mouse blastocysts (Smith, 1968) and binds to the cytosol of rabbit blastocysts (Bhatt \& Bullock, 1974). Its importance in rabbit embryonic development has been inferred from studies with the antioestrogen, CI-628. (1) Treatment of rabbit blastocysts with CI-628 interfered with implantation (Bhatt \& Bullock, 1974). (2) An intrauterine injection of CI-628 on Day 5 not only reduced by half the number of rabbit blastocysts recovered on Day 6 but also caused degenerative changes in the recovered blastocysts (Dey, Dickmann \& Sen Gupta, 1976). However, a $66 \%$ reduction in oestradiol production by rabbit blastocysts in culture caused no measurable effects on their growth. Similarly, the presence of the androstenedione aromatase inhibitors in the uterine lumen from Day 5 did not interfere with blastocyst implantation. It is possible, but unlikely, that androstenedione or its metabolites induced implantation and so masked an effect of reduced oestrogen production. Marsh, Romanoff, Williams, Brodie \& Brodie (1982) showed that 4-OH-androstenedione was metabolized in vitro by rat ovarian microsomal preparations into 4 -hydroxytestosterone ( $20 \%$ of total radioactivity) and 4-hydroxyoestrone $(0.1 \%)$. But when injected into the rat, the major metabolites in the blood were $3 \beta$-hydroxyandrostane-4,17-dione $(5 \%)$ and 4 -hydroxytestosterone $(0 \cdot 1 \%)$. The latter inhibited in-vitro ovarian aromatization activity by $59 \%$ (Marsh et al., 1981). These metabolites probably exert little hormonal activity: 4-hydroxyandrogen exhibited no oestrogenic, anti-oestrogenic, progestational, antiprogestational or antiandrogenic activity in the rat (Brodie et al., 1977).

The functional significance of blastocyst oestrogen in rabbits remains unknown, although it could be involved in embryo-maternal communication and the maintenance of corpora lutea as in the pig (Flint, Burton, Gadsby, Saunders \& Heap, 1979). 
This study was supported by NIH Grant HD-12047. We thank Dr D. C. Collins and Dr K. Wright for the gift of antiserum ( $E_{2}$ TG-K), Dr M. H. Brodie and Dr J. Brodie for the aromatase inhibitors; and Dr K. I. H. Williams for advising us during the study.

\section{References}

Abraham, G.E., Swerdloff, R., Tulchinsky, D. \& Odell, W.D. (1971) Radioimmunoassay of plasma progesterone. J. clin. Endocr. Metab. 32, 619-624.

Antila, E., Koskinen, J., Niemelä, P. \& Saure, A. (1977) Steroid metabolism by mouse preimplantation embryos in vitro. Experientia 33, 1374-1375.

Bhatt, B.M. \& Bullock, D.W. (1974) Binding of oestradiol to rabbit blastocysts and its possible role in implantation. J. Reprod. Fert. 39, 65-70.

Borland, R.M., Erickson, G.F. \& Ducibella, T. (1977) Accumulation of steroids in rabbit preimplantation blastocysts. J. Reprod. Fert. 49, 219-224.

Brodie, A.M.H., Schwarzel, W.C., Shaikh, A.A. \& Brodie, H.J. (1977) The effect of an aromatase inhibitor, 4-hydroxy-4-androstene-3,17-dione, on estrogen-dependent processes in reproduction and breast cancer. Endocrinology 100, 1684-1695.

Brodie, A.M.H., Marsh, D.A., Wu, J.T. \& Brodie, H.J. (1979) Aromatase inhibitors and their use in controlling oestrogen-dependent processes. J. Steroid Biochem. 11, 107-112.

Chew, N.J. \& Sherman, M.I. (1975) Biochemistry of differentiation of mouse trophoblast: $\Delta^{s}, 3 \beta$-hydroxysteroid dehydrogenase. Biol. Reprod. 12, 351359.

Dey, S.K., Dickmann, Z. \& Sen Gupta, J. (1976) Evidence that the maintenance of early pregnancy in the rabbit requires "blastocyst estrogen". Steroids 28, 481-485.

Dickmann, Z., Dey, S.K. \& Sen Gupta, J. (1975) Steroidogenesis in rabbit preimplantation embryos. Proc. natn. Acad. Sci. U.S.A. 72, 298-300.

Dickmann, Z., Dey, S.K. \& Sen Gupta, J. (1976) A new concept: control of early pregnancy by steroid hormones originating in the preimplantation embryo. Vitams Horm. 34, 215-242.

Flint, A.P.F., Burton, R.D., Gadsby, J.E., Saunders, P.T.K. \& Heap, R.B. (1979) Blastocyst oestrogen synthesis and the maternal recognition of pregnancy.
In Maternal Recognition of Pregnancy (Ciba Fndn Symp. No. 64), pp. 209-228. Excerpta Medica, Amsterdam.

Gadsby, J.E., Heap, R.B. \& Burton, R.D. (1980) Oestrogen production by blastocyst and early tissue of various species. J. Reprod. Fert. 60, 409417.

George, F.W. \& Wilson, J.D. (1978) Estrogen formation in the early rabbit embryo. Science, N.Y. 199, 200201.

Grube, K.E., Gwazdauskas, F.C., Lineweaver, J.A. \& Vinson, W.E. (1978) Steroidogenic capabilities of the early mouse embryo. Steroids 32, 345-354.

Hoversland, R.C., Dey, S.K. \& Johnson, D.C. (1982) Aromatase activity in the rabbit blastocyst. J. Reprod. Fert. 66, 259-263.

Marsh, D.A., Romanoff, L., Williams, K.I.H., Brodie, H.J. \& Brodie, A.M.H. (1982) Synthesis of deuterium and tritium labelled 4-hydroxy-4androstene-3,17-dione, an aromatase inhibitor, and its metabolism in vitro and in vivo in the rat. Biochem. Pharmacol. 31, 701-705.

Sherman, M.I. \& Atienza, S.B. (1977) Production and metabolism of progesterone and androstenedione by cultured mouse blastocysts. Biol. Reprod. 16, 190-199.

Singh, M.M. \& Booth, W.D. (1978) Studies on the metabolism of neutral steroids by preimplantation rabbit blastocysts in vitro and the origin of blastocyst oestrogen. J. Reprod. Fert. 53, 297-304.

Smith, D.M. (1968) The effect on implantation of treating cultured mouse blastocysts with oestrogen in vitro and the uptake of $\left[{ }^{3} \mathrm{H}\right]$ oestradiol by blastocysts. J. Endocr. 41, 17-29.

Wright, K., Collins, D.C. \& Preedy, J.R.K. (1978) The use of specific radioimmunoassays to determine the renal clearance rates of estrone and $17 \beta$ estradiol during the menstrual cycle. J. clin. Endocr. Metab. 47, 1084-1091. 